\title{
Contribution of Borehole Digital Imagery in Core-Log-Seismic Integration
}

\author{
by Philippe Gaillot, Tim Brewer, Philippe Pezard, and En-Chao Yeh
}

\section{Introduction}

The Integrated Ocean Drilling Program (IODP) and the International Continental Drilling Program (ICDP) use many new technologies to increase the quality of core data. A problem with drilling deep oceanic or continental crust, as well as shallow fractured rock or karstic formations, is that core recovery can be low, and much of the recovered material often consists of small, disrupted core pieces that are frequently biased toward particular types of rocks (lithologies). Even when core recovery is high (in the case of sedimentary formation), recovered cores are not always oriented; as a result, detailed structural and paleomagnetic studies are impaired.

In contrast, logging provides nearly continuous records of the in situ chemical and physical properties of the penetrated formation, which can be used to extrapolate the various lithologies in areas of reduced core recovery (Brewer et al., 1998).
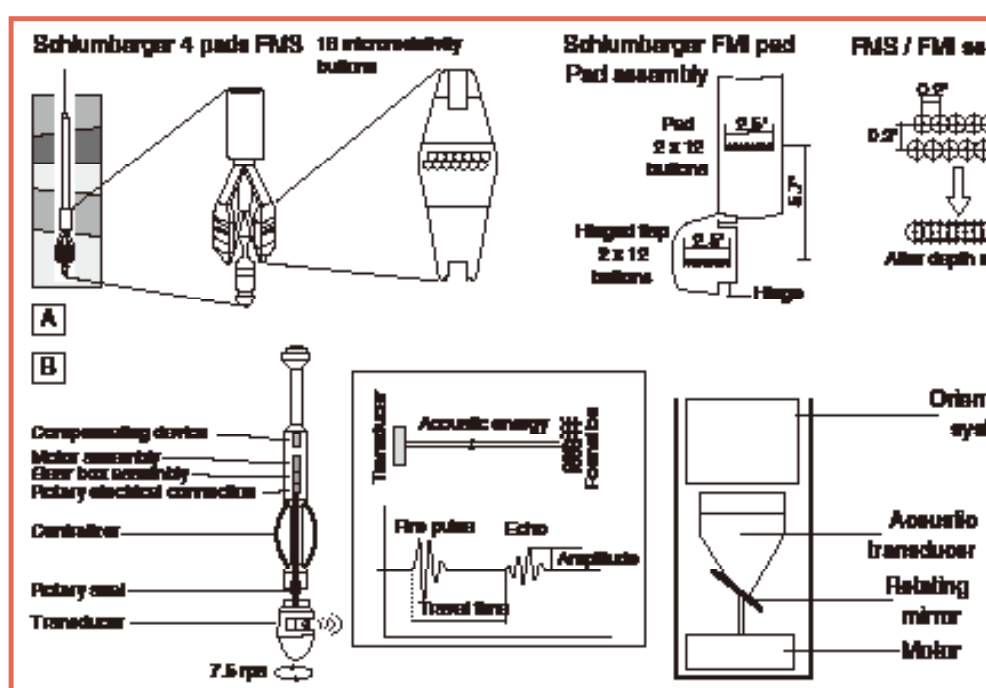

Ditantily

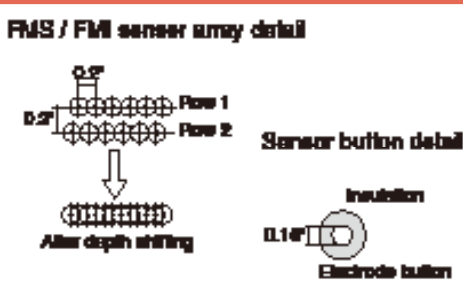

$\mathbf{G}$

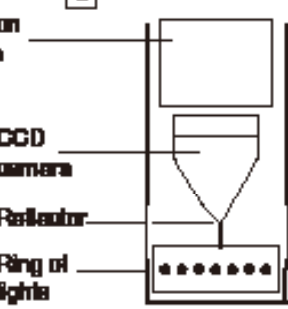

With the advent of modern imaging tools, a fundamentally new concept has been introduced (Serra, 1989; Lovell et al., 1998). Formations are no longer scanned by a single sensors creating a single scalar log, but can be sampled multiple times horizontally and at a high rate vertically to form a dense matrix of measurements being displayed as an image. Since the mid-eighties there has been an explosive development in imaging technology, principally in terms of tools but also in terms of producing the image. The progress has been linked with the availability of downhole digitization of signals and the possibility of transmitting large data volume in real time. Where the standard logs are sampled every $\sim 15 \mathrm{~cm}$ (6"), image logs may be sampled every $\sim 0.25 \mathrm{~cm}\left(0.1^{\prime \prime}\right)$ or less; where the standard logs have one measurement per depth point, image logs may have 360 or more.

So, digital borehole images (mm-scale) can potentially bridge the scale gap between the (dm-scale) standard logs and ( $\mu \mathrm{m}$ to dm-scale) core measurements. Indeed, continuous and oriented borehole wall images provide high resolution lithologic, textural, and structural information, filling information gaps where core recovery is low and allowing orientation of cores when core recovery and undoubted features are recognized on both core and logging images. In turn, continuous and quantitative information extracted from these images can help in bridging the scale gap between $\log$ and the large scale (macroscopic, $>100 \mathrm{~m}$ ) properties of the penetrated formation. While physical principles and applications of electrical, acoustic, and optical borehole imaging tools are easily schematized in Fig. 1 (see http:// publications.iodp.org/sd/05/ suppl/ for details), the present paper shows some examples of quantitative analyses of electrical images that illustrate various contributions of borehole images to a fully inte- 
grated core-log-seismic integration workflow.

\section{Case Studies}

Borehole images filling lithostratigraphic core gaps: Electrical borehole wall images acquired with theSchlumberger Formation MicroScanner (FMS) in Ocean Drilling Program (ODP) Hole 896A are a good example of the contribution of borehole images to reconstruct the lithostratigraphy when core recovery is low (<30\%) (ODP Leg 148 Shipboard Scientific Party, 1993; Alt et al., 1996). The alternative lithostratigraphy that is constructed by combining standard scalar logging data and FMS images contains considerably more brec-

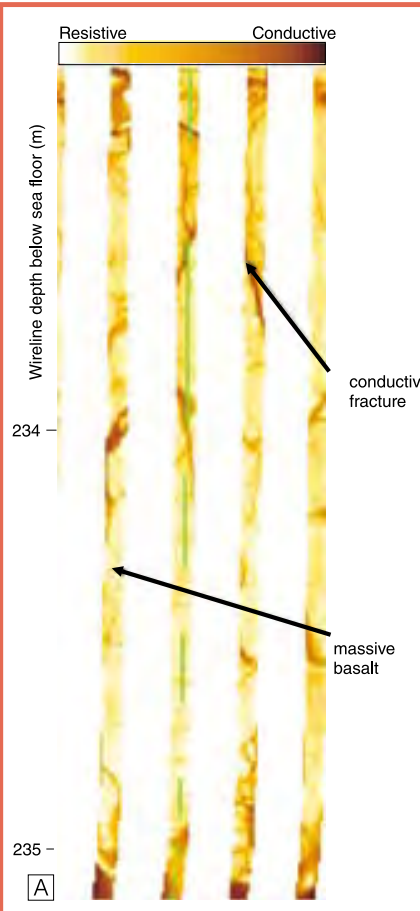
Figure 2. Formation MicroScanner (FMS) electrical images from ODP Hole 896A. [A] massive flow, [B]
pillow lava, and [C] brecciated material.
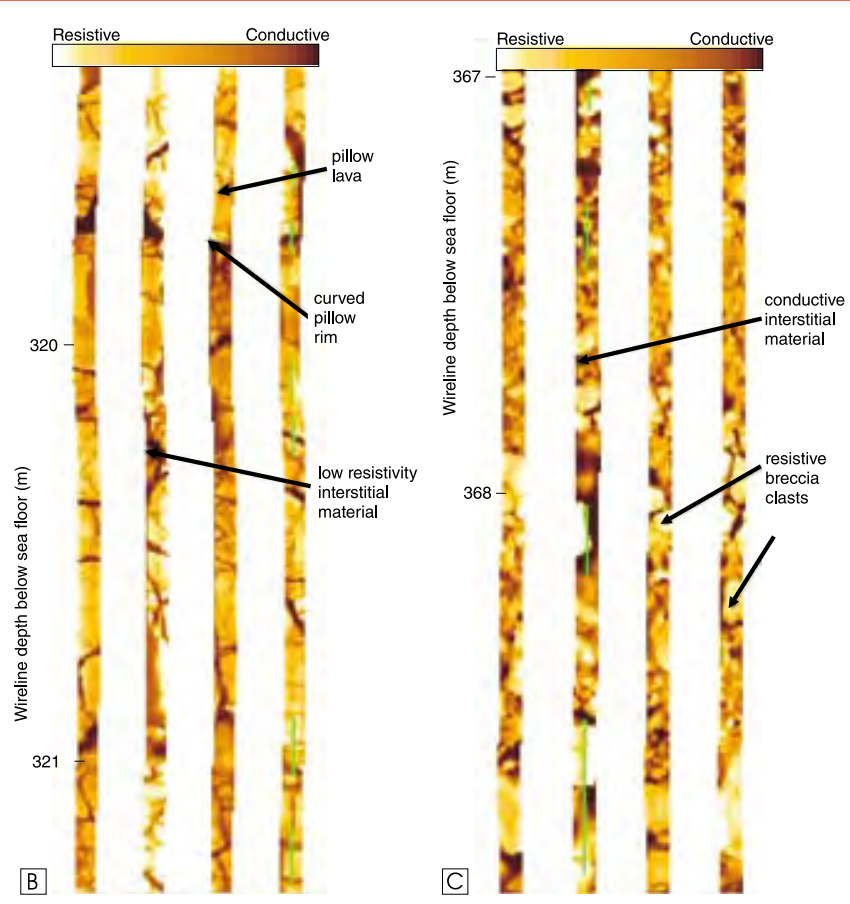

ciated units $(\sim 30 \%)$ than suggested by the shipboard core descriptions (10\%). This disparity, explained as the reflection of preferential recovery of less fractured massive flows, emphasized the necessity to fully integrate core and logging results in boreholes with reduced core recovery. In Hole 896A, different volcanic lithologies can be identified on the FMS image data by variations in electrical conductivity (Fig. 2). Massive units appear on the FMS images as extensive areas with a uniformly low conductivity and predominantly straight, branching fracture patterns (Fig. 2A). Pillow lavas show variable conductivity within a small area, but this is less variable than for brecciated units. Individual pillow lavas can often be distinguished on the FMS data owing to the curved nature of the pillow boundaries (Fig. 2B). Interstitial material usually has high conductivity. Breccias are characterized on the FMS image data by high conductivity, which is highly variable within a small area. The presence of small high-resistivity clasts can often be noted (Fig. 2C).

Orientation of cores using borehole images: In a more general manner, although cores obtained through ocean and continental drilling provide valuable information, recovered core pieces are often initially inaccurately located and unoriented in a geographical reference frame. In these situations, logging image data are essential to supplement and enhance structural data from the recovered core. One core imaging tool used by ODP during ODP Leg 176 was a digital core scan device that produces $360^{\circ}$ images of the outside of the core (Dick et al., 1999). These digital photographs can be unwrapped and displayed as 2-D images showing the core's entire outer surface (Fig. 3). The images can then be used to locate and measure the dip and orientation of structural features (veins, fractures, boundaries between different rock types) in the core. Assuming that the core recovery is high enough and features on core and borehole wall images are distinctive enough, such structural features on the core and logging FMS images can be matched and so allow the accurate location and orientation of individual core pieces, a key step in structural and paleomagnetic studies (MacLeod et al., 1995; Harvey and Lovell, 1998; Haggas et al., 2001). In the San Andreas Fault zone, Iturino et al (2001) used a combination Logging While Drilling (LWD) Resistivity At the Bit (RAB) image and core x-ray computed tomography images.

Formation scale information deduced from borehole images: Any paleoenvironmental reconstruction or investigation of large-scale geological bodies (through, upper oceanic crust, reservoir) requires the extension of the $1-\mathrm{D}$ view of the borehole to a regional-formation scale view. The first step involves a classification of the core and downhole log responses into relatively homogeneous sub-groups (units) based on (1) a lithofacies determination relying on visual core description and measurement (core units) and (2) a visual or statistical analysis of available logging data (log units). Due to the in situ and continuous nature of downhole data in respect to expensive and discontinuous nature of core data, methods based on multivariate statistics of downhole log response (electro-facies-based classification; See Ravenne, 2002 for a review.) have been developed to estimate spatial distribution of heterogeneous subsurfaces (e.g., regionalized classification relying on statistical relationships between laboratorydetermined hydrologic properties and field-measured geophysical properties to estimate spatial distributions of porosity, permeability, and diagenetic characteristics; Moline and Bahr, 1995). Such methods aim to predict the lithology 
of the penetrated formation, but more widely attempt to provide additional formation-scale hydrologic (flow unit, reservoir permeability) or geologic (structural, environmental) information. Taking into account the increase in computational power and the higher resolution and coverage of the borehole images in respect to standard logs, such methods have been generalized to include borehole images information (e.g., texture) and have been coupled to modeling tools.

Core, borehole image, log, and formation-scale integration: Log data and digital borehole images collected from the Hole-B of the ICDP Taiwan Chelungpu-fault Drilling Project have been analyzed to establish the relationships between deformation structures and in situ stress, and to identify the rupture zone of the $7.6 \mathrm{Mw}$ 1999 Chi-Chi earthquake. Based on standard

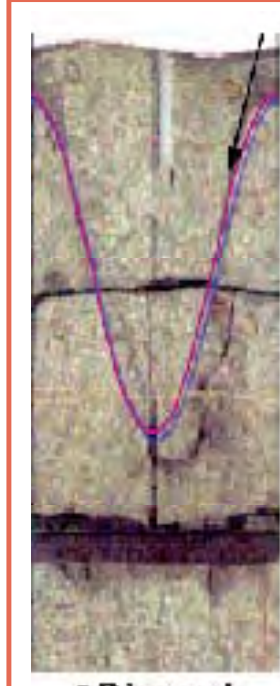

2-D innea of

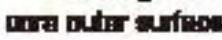

Reorientation of core from ODP Leg 176 using correlation with a fracture imaged by the Formation MicroScanner (FMS) electrical resistivity image tool (Modified from Haggas et al., 2001). scalar logs, three log units and five subunits are recognized as consistent with lithological units defined from visual core description (Fig. 4). Analysis of the Schlumberger Fullbore Formation MicroImager (FMI) resistivity data has also been automatically performed. This analysis, relying on the local and multi-scale properties of the wavelet transform formalism, consists in measuring the number and characteristics (size and electrical contrast) of each electric feature recorded in the high resolution logs, and so provides new high resolution "quantitative and integrative" logs—namely, the density of electrical features (Npm), the average size (wavelength, W) and average electrical contrast (C) of the detected features. In turn, combined with visual interpretation of sedimentary and structural features recognized on borehole images, these logs can be correlated to large-scale formation units and fault zones independently defined from the scalar logs and core data providing extra small-scale information on the nature of the downhole variations in natural gamma radiation (NGR), electrical resistivity, and sonic velocity (Vp) (Fig. 4).

\section{Conclusion}

Digital borehole images have the same depth coverage of scalar logs, with a resolution higher than these logs and often higher than standard core logging measurements. Relying on different physical bases, imaging tools provide a palette of high resolution, continuous, and oriented $360^{\circ}$ views of the borehole wall from which the character, relation, and orientation of lithologic and structural planar features, as well as texture, can be defined to support detailed core analyses. Analyzed with specific methods relying on multivariate statistics or automatic extraction of quantitative attributes, these images and high resolution information derived from them allow filling the scale gap between core/sample measurements and large-scale formation properties, thus opening an avenue in addressing scientific challenges related to formation characterization.

\section{References}

Alt, J.C., Kinoshita, H., Stokking, L.B., and Michael, P.J. (Eds.), 1996. Proc. ODP, Sci. Results, 148. College Station, Texas (Ocean Drilling Program).

Brewer, T.S., Harvey, P.K., Lovell, M.A., Haggas, S., Williamson, G., and Pezard, P., 1998. Ocean floor volcanism: constraints from the integration of core and downhole logging measurements. Geol. Soc. Lond., Spec. Publ., 136:341-362.

Dick, H.J.B., Natland, J.H., Miller, D.J., et al., 1999. Proc. ODP, Init. Repts., 176 [Online]. Available from http://www-odp.tamu. edu/publications/176_IR/176TOC.HTM.

Ekstrom, M. P., Dahan, C. A. Chen, M. Lloyd, P. M. and Rossi, D. J., 1987. Formation imaging with microelectrical scanning arrays. Log Analyst, 28, 294-306.Haggas, S., Brewer, T.S., Harvey, P.K., and Iturrino, G., 2001. Relocating and orienting cores by the integration of electrical and optical images: a case study from Ocean Drilling Program Hole 735B. J. Geol. Soc. (London, U.K.), 158:615-623.

Haggas, S., Brewer, T.S., Harvey, P.K., and Iturrino, G., 2001. Relocating and orienting cores by the integration of electrical and optical images: a case study from Ocean Drilling Program Hole 735B. J. Geol. Soc. (London, U.K.), 158:615-623.

Harvey, P.K., and Lovell, M.A., (Eds.), 1998. Core-Log Integration. Geol. Soc. Spec. Publ., 136, 400 pp.

Iturino, G.J., Goldberg, D., and Ketcham, R., 2001. Integration of core and downhole images in the San Andreas fault zone. EarthScope Workshop: Making and Breaking a Continent, Snowbird, Utah, 10-12 October 2001. Abstract online at http://www.scec.org/instanet/01news/es_abstracts/Iturrino_et_al.pdf.

Leg 148 Shipboard Scientific Party, 1993. Site 504. In Alt, J.C., Kinoshita, H., Stokking, L.B., et al., Proc. ODP, Init. Repts., 148. College Station, Texas (Ocean Drilling Program), 27 121. Available online at http://www-odp.tamu.edu/publications/148_IR/VOLUME/CHAPTERS/ir148_02.pdf.

Lovell, M.A., Harvey, P.K., Brewer, T.S., Williams, C., Jackson, P.D., and Williamson, G., 1998. Application of FMS images in the Ocean Drilling Program: an overview. In Cramp, A., 


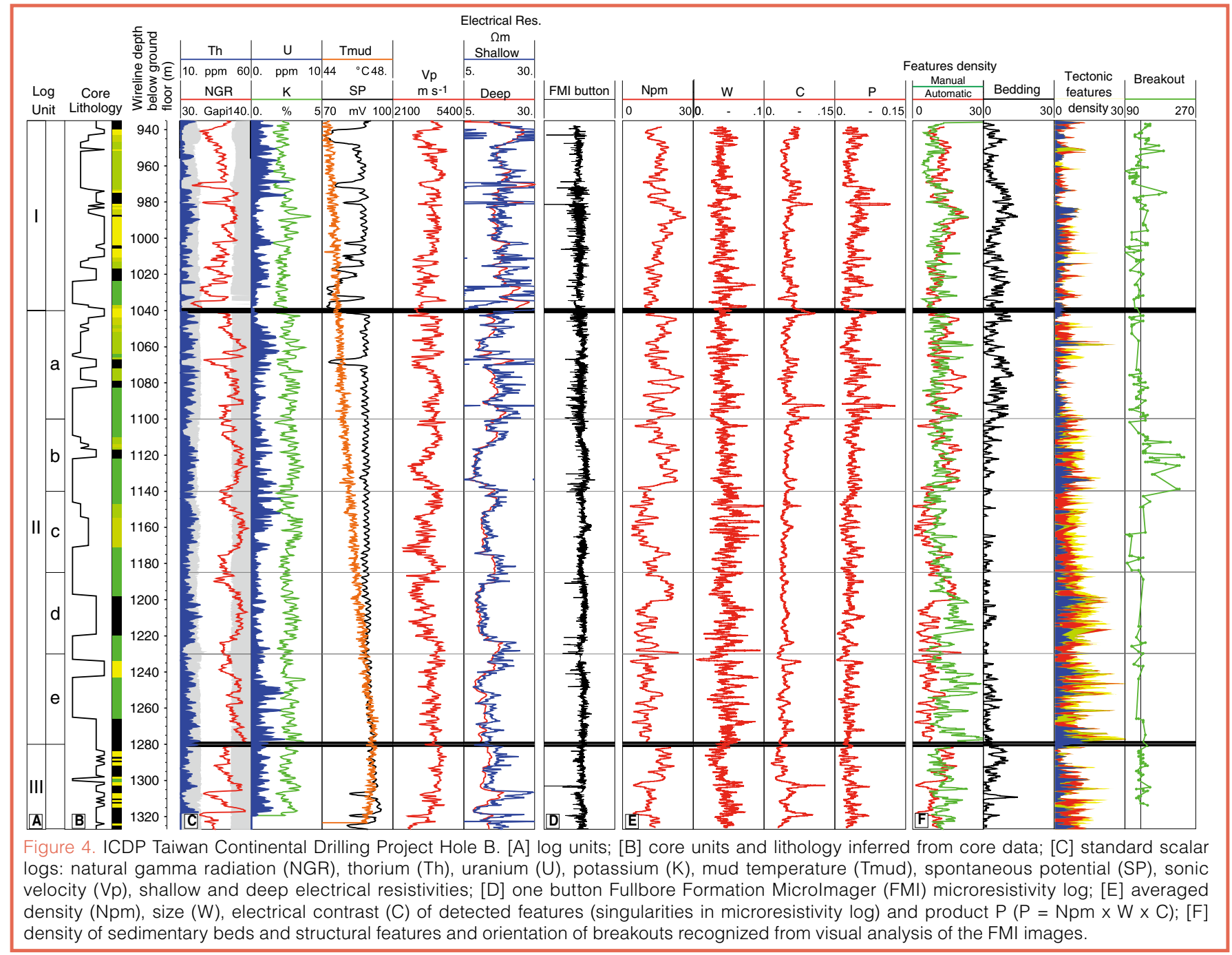

MacLeod, C.J., Lee, S.V., and Jones, E.J.W. (Eds.), Geological Evolution of Ocean Basins: Results from the Ocean Drilling Program. Geol. Soc. Spec. Publ., 131:287-303.

MacLeod, C.J., Célérier, B., and Harvey, P.K., 1995. Further techniques for core reorientation by core-log integration: application to structural studies of lower oceanic crust in Hess Deep, eastern Pacific. Sci. Drill., 5:77-86.

Moline, G.R., and Bahr, J-M., 1995. Estimating spatial distributions of heterogeneous subsurface characteristics by regionalized classification of electrofacies. Mathemat. Geol., 27(1):3-22.

Ravenne, Ch., 2002. Stratigraphy and oil: a review, part 2 characterization of reservoirs and sequence stratigraphy: quantification and modeling. Oil Gas Sci. Technol. Rev. IFP, 57:(4):311-340.

Serra, O., 1989. Formation MicroScanner Image Interpretation. Houston, Texas (Schlumberger Educational Services), SMP-7028.

\section{Authors}

Philippe Gaillot, CDEX-IFREE, Japan Agency for MarineEarth Science and Technology, Yokohama Institute for Earth Science, 3173-25 Showa-machi, Kanazawa-ku, Yokohama, Kanagawa, 236-0001 Japan, e-mail: gaillotp@jamstec.go.jp.

Tim Brewer, Department of Geology - Geophysics and Borehole Research, University of Leicester, University Road, Leicester, LE1 7RH, U.K.
Philippe Pezard, Laboratoire de Géophysique et d'Hydrodynamique en Forage, Geosciences Montpellier, University of Montpellier 2, France.

En-Chao Yeh, Department of Geosciences, National Taiwan University, No.1, Sec. 4, Roosevelt Road, Taipei 106, Taiwan.

\section{Related Web Links}

http://dx.doi.org/10.2204/iodp.proc.310.2007 http://dx.doi.org/10.2973/odp.proc.ir.176.1999

http://www.scec.org/instanet/01news/es_abstracts/ Iturrino_et_al.pdf

Co-author Dr. Tim Brewer collapsed and died on Saturday morning, 14th July, 2007, while attending a conference in Barcelona. This is obviously shocking and very sad news and came as a complete surprise to everyone.

Tim was a senior member of staff in the Department of Geology at the University of Leicester but also the lead coordinator in the European Petrophysical Consortium, part of the ECORD Science Operator for the Integrated Ocean Drilling Program.

He will be sadly missed by his friends and colleagues around the world. 